\title{
Polyunsaturated Fatty Acids (PUFA) and the Prospects for the Development of Aquaculture
}

\author{
Joanna Nowosad* and Dariusz Kucharczyk \\ Department of Lake and River Fisheries, University of Warmia and Mazury in Olsztyn, Poland
}

Submission:March 26, 2017; Published: May 02, 2017

*Corresponding author: : Joanna Nowosad, Department of Lake and River Fisheries, University of Warmia and Mazury in Olsztyn, Poland;

Email: nowosad.joanna@gmail.com

\section{Mini Review}

Finfish are an important source of easily-digestible proteins and unsaturated fatty acids for humans. Fish should ensure proper food from adult individuals, fry and larvae before commencing exogenous nutrition. In recent years, there has been a growing demand for aquaculture products, which imposes on breeders the need to increase production and ensure an adequate quantity and expected quality of commercial material for consumers [1,2]. On the other hand, conservative aquaculture requires providing stocking material (larvae, juveniles) in order to strengthen or initiate natural fish populations. In both cases, the culture material, intended for further breeding, as well as stocking, should be of high quality, understood as individuals in a fit condition and health. Fish with injuries, without scales, dimensionally smaller or deformed (Figure 1) are often unattractive to the consumer and raise concerns that they may be contaminated or sick.

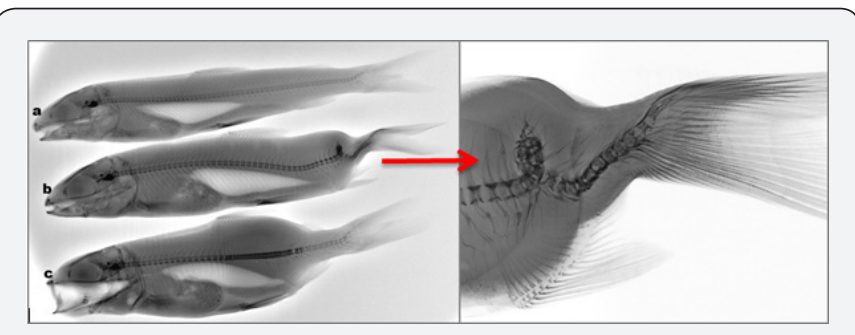

Figure 1: Body and skeleton deformation of whitefish (Coregonus lavaretus) juveniles, which was fed with inappropriate artificial feed. Non-deformed fish (a) and fish with deformed spine in the tail (b) and lumbar (c) part. Arrow indicates strongly skeleton deformation.

From the point of view of conservative aquaculture (stocking), material in bad condition, characterized by weak energy and deformities, can be very easy prey for potential predators. Therefore, in addition to maintaining appropriate conditions for rearing larvae, a key aspect appears to be appropriate feeding, in order to ensure adequate nutrients for their development. The results of many studies have shown that the increased levels of unsaturated fatty acids in the feed affect the efficiency of breeding, including the quality and fertility of gametes, the percentage of the hatching larvae and their quality (no deformation of the body, increase in resistance to stress) and, during the rearing juvenile stages, increases the survival rate, growth rate and stress resistance. Well-fed brood, not only has a high survival rate (over $90 \%$ ), but is also resistant to adverse environmental change and pathogens.

The development of aquaculture also requires seeking new technical solutions that reduce production costs. In this regard, a good solution is provided by recirculation aquaculture systems (RAS), which allow you to control environmental and sanitary conditions $[3,4]$, as well as the reuse of water, so you can reduce water consumption and minimize waste [3]. Despite many comforts for fish RAS farming, breeders must continue to ensure adequate sanitation (cleaning faeces and uneaten feed residues) and ensure adequate food adapted to the preferences of cultured species. Properly selected food not only includes the survival and growth of fish, but also the health condition. It should be noted that although aquaculture is developing, there is still no proper feed, especially starters for different fish species, and feeding remains the largest part of production costs.

Fish meal and oil are the major (and most expensive) components of fish feed [1]. Feed manufacturers seek to reduce the cost of feed by replacing fish meal with other meals, e.g. feather, poultry, soybeans, or corn. However, fish oil, due to the fatty acid omega-3, appears to be a crucial component in fish feed. In recent years, there has been a trend towards enriching fish feed with amino acids [5], vitamins [6], probiotics [7] as well as polyunsaturated fatty acids (PUFA) (mainly omega-3) $[6,8,9]$. The enrichment process was done mainly for natural 
food (Artemia sp., Rotifers, blood worms) for feeding larvae and juveniles as well as artificial feeds designed for juveniles and spawners. Polyunsaturated fatty acids are important in feeding the fish because, to date, a number of Omega- 3 acids have been proven to have a positive impact on the human body. The group of Omega-3 includes, among others, docosahexaenoic acid (DHA) andeicosapentaenoic acid (EPA). These essential fatty acids, among others: reduce the risk of atherosclerosis, improve blood pressure, prevent blood clots and have anti-inflammatory, anti-depressant and anti-cancer properties [10]. While in fish, beneficial effects of these fatty acids were found on both reproduction and larvae development. It has been proven that in the case of spawning fish (e.g.: zebrafish, Danio rerio [11] ide, Leuciscus idus [12]) fed food enriched in polyunsaturated fatty acids, a larger proportion of females proceed to reproduction (ovulation occurs) and are often characterized by higher fertility. Such fish larvae have both a higher survival rate and growth [11]. In addition, fish with high levels of essential fatty acids (PUFA) may be a source of this compound for the human diet as a functional food improving or maintaining appropriate health status.

\section{References}

1. Tran TTN, Lebailly P (2017) On Sustainable Aquaculture. Fish \& Ocean Opj 1(3).

2. Sunil KP (2017) Review of World Aquaculture and Oceanography. Fish \& Ocean Opj 1(3).

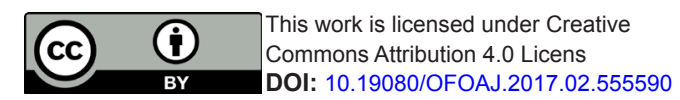

3. Lazur AM, Britt DC (1997) Pond Recirculating Production Systems. Pub South Reg Aquacult Cent No. 455.

4. Żarski D, Kucharczyk D, Targońska K, Krejszeff S, Czarkowski T, et al. (2010) Dynamics of nitrogen and phosphorus in closed and semiclosed recirculating aquaculture systems during the intensive culture of goldfish, Carassius auratus auratus (L.), juveniles. Arch Pol Fish 18: 187-193.

5. Zhang DM, Yoshimatsu T, Furuse M (2005) Effects of l-carnitine enrichment on the population growth, egg ratio and body size of the marine rotifer, Brachionus rotundiformis. Aquaculture 248(1-4): 51-57.

6. Gapasin RSJ, Bombeo R, Lavens P, Sorgeloos P, Nelisc H (1998) Enrichment of live food with essential fatty acids and vitamin C: effects on milkfish (Chanos chanos) larval performance. Aquaculture 162(34): $269-286$

7. Banerjee G, Ray AK (2017) The advancement of probiotics research and its application in fish farming industries. Res Vet Sci 115: 66-77.

8. Rollo A, Sulpizio R, Nardi M, Silvi S, Orpianesi C, et al. (2006) Live microbial feed supplement in aquaculture for improvement of stress tolerance. Fish Physiol Biochem 32(2): 167-177.

9. Lubzens E, Zmora O, Barr Y (2001) Biotechnology and aquaculture of rotifers Hydrobiologia 446(1): 337-353.

10. Materac E, Marczyński Z, Bodek KH (2013) The role of long-chain fatty acids omega- 3 and omega- 6 in human body Bromat. Chem Toksykol -XLVI(2): 225-233.

11. Nowosad J, Kucharczyk D, Targońska K (2017) Enrichment of zebrafish Danio rerio (Hamilton, 1822) diet with PUFAs improves fecundity and larvae quality. Zebrafish (in press).

12. Król R, Targońska K, Nowosad J, Kujawa R, Kupren K, et al. (2014) Effect of environmental conditions and feeding on the effectiveness of ide Leuciscus idus (L.) reproduction. Wulf J 21(2): 125-135.

\section{Your next submission with Juniper Publishers will reach you the below assets}

- Quality Editorial service

- Swift Peer Review

- Reprints availability

- E-prints Service

- Manuscript Podcast for convenient understanding

- Global attainment for your research

- Manuscript accessibility in different formats ( Pdf, E-pub, Full Text, Audio)

- Unceasing customer service

Track the below URL for one-step submission 